\title{
ONE FOR ALL AND ALL FOR ONE: LINEAR REGRESSION FROM THE MASS OF INDIVIDUAL BONES TO ASSESS HUMAN SKELETAL MASS COMPLETENESS
}

Gonçalves $\mathrm{D}^{1-3}$, d'Oliveira Coelho $\mathrm{J}^{3}$, Acosta $\mathrm{MA}^{3}$, Coelho $\mathrm{C}^{3}$, Curate $\mathrm{F}^{1,4}$, Ferreira $\mathrm{MT}^{1,3,5}$, Gouveia $M^{5}$, Makhoul $C^{3}$, Pinto $D^{5}$, Santos $1 O^{3}$, Vassalo $A R^{3}$, Navega $D^{3}$, Cunha $E^{3,5}$

${ }^{1}$ Research Centre for Anthropology and Health (CIAS), Department of Life Sciences, University of Coimbra. Calçada Martim Freitas, 3000-456, Coimbra, Portugal.

${ }^{2}$ Archaeosciences Laboratory, Directorate General for Cultural Heritage and LARC/CIBIO/InBIO, Rua da Bica do Marquês 2, 1300-087 Lisboa, Portugal.

${ }^{3}$ Centre for Functional Ecology, Laboratory of Forensic Anthropology, Department of Life Sciences, University of Coimbra, Calçada Martim Freitas, 3000-456, Coimbra, Portugal.

${ }^{4}$ Interdisciplinary Center for Archaeology and Evolution of Human Behavior, University of Algarve, Faro, Portugal.

${ }^{5}$ Department of Life Sciences, University of Coimbra. Calçada Martim Freitas, 3000-456, Coimbra, Portugal.

Abstract

\section{Objectives}

Complete and accurate human skeletal inventory is seldom possible in archaeological and forensic cases involving severe fragmentation. In such cases, skeletal mass comparisons with published references may be used as an alternative to assess skeletal completeness but they are too general for a case-by-case routine analysis. The objective is to solve this issue by creating linear regression equations to estimate the total mass of a skeleton based on the mass of individual bones.

\section{Material and Methods}

Total adult skeletal mass and individual mass of the clavicle, humerus, femur, patella, carpal, metacarpal, tarsal and metatarsal bones were recorded in a sample of 60 skeletons from the $21^{\text {st }}$ century identified skeletal collection (University of Coimbra). The sample included 32 females and 28 males with ages ranging from 31 to 96 years old ( mean $=76.4 ; \mathrm{sd}=14.8$ ). Skeletal mass linear regression equations were calculated based on this sample.

\section{Results}

The mass of individual bones was successfully used to predict the approximate total mass of the adult skeleton. The femur, humerus, and second metacarpal were the best predictors of total skeletal mass with root mean squared errors ranging from 292.9 to $346.1 \mathrm{gm}$. 


\section{Discussion}

Linear regression was relatively successful at estimating adult skeletal mass. The non-normal distribution of the sample in terms of mass may have reduced the predictive power of the equations. These results have clear impact for bioanthropology, especially forensic anthropology, since this method may provide better estimates of the completeness of the skeleton or the minimum number of individuals.

Keywords: bioarchaeology; forensic anthropology; bone mass; scattered remains; funerary practice.

The objective of this paper is to investigate the potential of linear regression to estimate the mass of human adult skeletons based on the mass of individual bones. In some cases involving skeletal remains, it may be difficult to assess how complete the skeleton is due to fragmentation that prevents the anatomical identification of all skeletal elements. For example, it may be difficult to estimate the minimum number of individuals (MNI) or decide when to conclude forensic searches for the remains of victims when it is impossible to determine the amount of missing bones, especially if the remains are very fragmented, commingled and/or scattered. Such inventory problems are often more complicated still in cases involving burned skeletal remains. In the case of archaeological cremations, an exhaustive inventory is often impossible to accomplish due to the high number of anatomically unidentified fragments (Gonçalves et al, 2015). Therefore, unorthodox methods to assess skeletal completeness are worth exploration.

To our knowledge, the only alternative method to assess skeleton completeness is by weighing remains to provide an estimate of skeletal mass. This is then compared with references obtained from samples of complete adult skeletons (e.g. Ingalls, 1931; Lowrance and Latimer, 1957; Silva et al., 2009). However, such comparisons suffer from high variability due to the fact that skeletal mass is exceedingly variable across individuals due to such variables as ancestry, sex, age at death, and some diseases, such as osteoporosis, that affect skeletal mass (Bass and Jantz, 2004; Van Deest et al., 2011; May, 2011; Gonçalves et al., 2013). Skeletal mass at the individual level also varies due to differences in stature, body mass index, and bone mass density, amongst other factors (Warren and Maples, 1997; Chirachariyavej et al., 2006; May, 2011; Van Deest et al., 2011). Therefore, due to such variability, specific reference for comparison may not only be inexact, but downright misleading. We seek to resolve this problem by developing a method to estimate the mass of a skeleton on a case-by-case basis.

The approach presented in this paper consists of obtaining the mass of the complete skeleton by weighing some of its specific bones. To accomplish this goal, linear regression models must be developed from a sample of relatively complete skeletons. With this methodology it is possible to compare the mass of the recovered remains against its original estimated mass. Only then, can the appraisal of skeletal completeness and scattering be reliably established. Similar attempts to estimate total skeletal mass have been attempted by Matiegka 
(1921) and Trotter (1954). However, in those studies, estimations were based on the metrics of long bones. Baker and Newman (1957) were the first to apply the procedure here investigated and argued that dry bone mass could eventually enable the reunion of scattered bones from the same skeleton. They found significant correlations between the mass of several bones and the total mass of the skeleton and created regression equations to estimate the latter. However, these authors used the skull as well as right hip bones and long bones to develop their equations on both european and african male americans. The resulting equations have little applicability because they: 1 ) are based exclusively on male skeletons; 2 ) are ancestry-specific; 3 ) are based on bones that are very susceptible to fragmentation or/and that are often reallocated to secondary locations; and 4) refer only to the right antimeres. We propose to follow the same approach with smaller bones, from individuals of both sexes and from the left and right sides of the skeleton, that tend to be left behind during the reallocation of primary skeletal depositions (Roksandic, 2002; Duday and Guillon, 2006) or that preserve well in very fragmented assemblages, such as those of the patella, hand, and feet (Delfleur et al., 1999; Gonçalves, 2011).

If regression analyses are proven useful, this kind of approach may bring an important benefit to the analysis of human skeletal remains. In archaeological and forensic contexts, it will help the investigator to estimate skeletal completeness in cases where fragmentation is severe. This method could also potentially assist in estimating the MNI since more than one individual can be inferred from the presence of unusually heavy assemblages of skeletal remains (Gonçalves et al., 2015). Indeed, skeletal mass has been used repeatedly in bioarchaeological analyses for that very purpose (e.g., Duday et al., 2000; Ubelaker and Rife, 2007; André et al., 2013). Although seldom explored due to its limited applicability, skeletal adult mass is sexually dimorphic and, according to some investigators (Warren and Maples, 1997; Van Deest et al., 2011; Quatrehomme, 2015), can hypothetically be used to predict sex of unknown individuals. Besides these potential applications, the possibility of predicting the mass of the entire skeleton based on a single skeletal element is, by itself, a step forward in physical anthropology.

\section{MATERIAL AND METHODS}

The investigation focused on the $21^{\text {st }}$ century identified skeletal collection (CEI/XXI) housed at the Department of Life Sciences, University of Coimbra, Portugal (Ferreira et al., 2014). The fact that these skeletons are from individuals who died in recent times was beneficial to this research, since it avoided possible major biases in skeletal mass that may be related to post-depositional differential skeletal mass loss or secular trend. At the time of the study the collection encompassed 236 skeletons.

A sample of 60 adult skeletons of both sexes was examined. It comprised 32 females with ages ranging from 38 to 96 years old (mean $=78.0 ; \mathrm{sd}=14.0$ ) and 28 males with ages ranging from 31 to 95 years old (mean $=74.0 ; \mathrm{sd}=15.5$ ). The sample included skeletons that were complete or almost complete. All skeletal elements were ideally present and wellpreserved, but exceptions were taken into consideration for the following: teeth, hyoid, sternum, hand and foot phalanges. This is for two reasons. First, due to the advanced age at death of the individuals composing the sample, skeletons were often almost or completely edentulous; as such, the presence of teeth was overlooked. Second, as for the remaining non- 
dental elements, these bones usually represent less than 3-4\% of the overall skeletal mass (Silva et al., 2009) so their absence was assumed to not alter results significantly.

Attention was given to certain bones, such as those of the hands and feet, the clavicle and the patella that usually preserve well in very fragmented assemblages, such as those composed of fossil remains or burned skeletal remains (Delfleur et al., 1999; Gonçalves, 2011), to investigate the association of the mass of each bone to overall adult skeletal mass. Other skeletal elements were selected because they are also weight bearing and hence may be more significantly correlated with skeletal mass. Therefore, the following individual bones from both sides were weighed: clavicle; tarsal bones; patella; metacarpals (MC), and metatarsals (MT). The left femur and left humerus were also weighed, although neither preserve well in very fragmented assemblages and despite the fact that the humerus is not a weight bearing element. As this was merely carried out as a comparison of their performance against the other skeletal elements there was no need to examine femoral and humeral antimeres.

The masses of the total skeleton and of each separate bone included in the research were documented by weighing it on a Kern PCB digital scale (version $1.5-02 / 2013$ ), which measures weight in $0.1 \mathrm{gm}$ increments. As a pre-analysis procedure, bilateral skeletal elements were investigated to determine whether significant asymmetries are present, for if elements differ significantly by side, then both sides of the skeleton must be treated separately during statistical analysis. However, if differences between elements of the left and right sides are statistically insignificant, then a missing skeletal element from one side may be replaced by its antimere, if present. Bilateral asymmetry was investigated through a Wilcoxon signed ranks test. Also, the relative directional asymmetry (\%DA), which has been often used previously (Steele and Mays, 1995; Mays, 2002; Auerbach and Ruff, 2006), was calculated for each individual so that a better notion of asymmetry in a case-by-case basis could be achieved. The formula used was the following:

$$
\% \mathrm{DA}=(\text { right }- \text { left }) /(\text { average of left and right }) * 100
$$

Linear regression analysis was carried out using R software (R Development Core Team, 2015). Regression analysis did not take age at death and sex into consideration because we intentionally assumed that total skeletal mass was directly reflected by the mass of each individual bone regardless of those variables. In other words, the working hypothesis was that any significant effect that age, sex, or any other variables may have in the mass of the skeleton has a roughly similar effect on each of the individual bones investigated in this paper. We called this the "one for all" assumption. Therefore, the mass of individual bones should always be significantly correlated with the total mass of the skeleton to which they belong. The working hypothesis is intentionally "naïve" since it has been demonstrated that bone mass is multifactorial (e.g. Bass and Jantz, 2004; Silva et al., 2009; May, 2011). However, we chose to prioritize applicability instead of precision. The advantage of such an approach is that if the regression equations significantly predict skeleton total mass, they can be applied to all cases involving human remains regardless of whether age-at-death, sex, ancestry, stature, or body 
mass of the individual is known in advance. This would be a major benefit because this information is often unknown in both archaeological and forensic contexts.

\section{RESULTS}

The third metacarpal was the only bilateral skeletal element found to be significantly asymmetric $(z=128.50, p<0.01)$ at the 0.01 level, with higher than expected mass for elements from the right side. Whether this difference is the consequence of statistical noise or some particular cause could not be determined. Nevertheless, most of the bilateral skeletal elements in the sample had a heavier ride-side member than its antimere. The only exceptions to this pattern were the clavicle, cuboid, third cuneiform, and third metatarsal. Excluding the last, which was heavier among left-side members (non-significantly), all other exhibited virtually no asymmetry (Table 1 and supplemental information). Although no significant differences in the mean mass of left- and right-side bilateral skeletal elements was found in almost all cases, large degrees of directional asymmetry was nonetheless present in a case-by-case basis (individual \%DA values varied from -43.478 to 47.610 ). Therefore, we decided to investigate each bone by side, rather than pool elements of the two sides into a single sample.

[Table 1 here]

Correlation matrices (provided as supplemental information) demonstrate that the variables are highly correlated with one another. Multicollinearity is an obstacle to create proper multivariable regression models, inducing variable redundancy (Maroco, 2014). Therefore, we have avoided these, since they would be of little use, with evident problems of overfitting and reduced applicability to real cases.

Table 2 reports univariate linear regression model parameters, including intercept and slope values as well as the root mean squared error (RMSE) and explained variance ( $r 2)$, for each of the skeletal elements analyzed in this study. Univariate regression models using the left femur, left humerus, left second metacarpal, and left clavicle were the most accurate at predicting total skeletal mass. Standard error for regression models using these three bones varied between 292.9 to $364.7 \mathrm{gm}$. The left fourth metacarpal yielded the least accurate results with an RSME value of $561.8 \mathrm{gm}$.

[Table 2 here]

\section{DISCUSSION}

Our results demonstrate that a pars pro toto relationship is present within the human skeleton. That is, the mass of an individual skeletal element is significantly correlated with the total mass of the skeleton and therefore the mass of this individual element can be used to predict the mass of the adult skeleton as a whole. This result had already been partially obtained by Baker and Newman (1957) on the femur, humerus, and clavicle. The actual predictions proved not to be as accurate for predicting total skeletal mass as anticipated and this is reflected 
by the relatively high RMSE values. Nonetheless, this approach can be considered more helpful than the alternative approach, which consists of rough comparisons with references for skeletal mass that are too variable and general for any meaningful application on a case-by-case basis. This is reflected by the fact that Ingalls (1931) found wide ranging variation in the skeletal mass of males, ranging from 2984 to $6976 \mathrm{gm}$. It would therefore be difficult to establish a reliable comparison by merely taking these references into consideration.

The greatest advantage of this regression method is that it may be used without prior knowledge of the biological profile or the body mass index of the individual. This is because the regression equation estimates the total skeletal mass intrinsically. Comparisons are not made against external references but rather by using data from the skeleton itself. This approach is therefore inherently more reliable in a case-by-case analysis. Skeletal mass references do offer one advantage that is absent in the regression approach: the regression equations cannot be applied to incomplete bones. In the case of skeletal mass references, their application does not require that any of the remains be anatomically identified.

Considering the results of the bilateral asymmetry analysis we expected that linear models obtained from the mean of the values of both bone sides in the same skeleton would create statistically sound models. However, we instead provided models for every bone separated by side. This is an indication that the equations proposed by Baker and Newman (1957) for left bones may not be appropriate for right bones. By weighing any single bone, any researcher can obtain an estimation of the total skeletal mass. This can be done either through hand calculation with the values provided in Table 2 or by accessing our web app (http://Ifa.uc.pt/MassReg/) that allows anyone with internet access to interactively obtain predictions. Go to "Predict" and select the desired bone and laterality ( $\mathrm{X}$ variable) to estimate the total adult skeletal mass ( $Y$ variable). Then, the mass of the selected bone must be inserted in the "your numeric input" field to do the regression. The results for the fit, minimum, and maximum values are presented in the "total skeleton mass" table. For example, if the mass of a left clavicle is $18.2 \mathrm{gm}$, the fit value will be $3196.91 \mathrm{gm}$. This value should then be compared with the actual mass of the entire skeletal assemblage to infer its completeness.

Total adult skeletal mass was best predicted by the masses of the femur and humerus. This finding was somewhat expected and could be particularly important for making inferences about the completeness of skeletons from both secondary depositions and disturbed primary depositions. This is because the femur and humerus are two resilient bones and tend to preserve very well (Waldron, 1987; Mays, 1992; Bello and Andrews, 2006). Consequently the MNI is often based on these two skeletal elements. Therefore, our femoral and humeral regression equations could be especially useful for providing a more reliable estimate of the original skeletal mass of such assemblages and thereby assist in the determination of how much of it is missing. However, if the humerus and femur are sufficiently intact to allow application of the regression equations, chances are that the assemblage is also sufficiently preserved to allow for the more reliable skeletal inventory. As a result, it is likely that the femoral and humeral equations will not prove to be the most useful among those that have been proposed here.

As mentioned previously, the skeletal mass approach is more helpful to assess skeletal completeness in very fragmentary assemblages because a comprehensive anatomical 
identification of all fragments is impossible to accomplish in these cases. Under such circumstances, it may be difficult to identify situations of partial removal of bones from primary depositions that were naturally or intentionally reallocated elsewhere. In such contexts, it is very likely to find smaller bones that have more labile joints since they are easily overlooked during the operation of reallocation (Roksandic, 2002; Duday and Guillon, 2006). Therefore, smaller bones may prove more helpful for making assessments of skeletal completeness. The left second metacarpal was the only smaller bone that presented an RMSE smaller than $350 \mathrm{gm}$.

The applicability of the regression equations may face yet another problem. The significant correlation between a given bone and total skeletal mass may be compromised significantly in cases where postmortem bone mass loss does not occur homogeneously throughout all parts of the skeleton. For example, bone degradation is anisotropic, in particular regarding its organic component (Willey et al., 1997; Collins et al., 2002). Also, differential damage within the same bone and within the same skeleton is not uncommon. Regrettably, this problem cannot be suitably solved by our regressions. However, it is not exclusive to this approach and also affects potential comparisons with published references for skeletal mass. At least, by estimating total mass based on one of the elements of the skeleton, a more direct estimation can be provided.

Regrettably, the age distribution of the individuals studied was not ideal. The sample was composed of a vast majority of skeletons from elderly individuals, a problem that is universal among all European collections of recently deceased identified skeletons (e.g. Kranioti et al., 2008; Rissech and Steadman, 2011; Madentzoglou et al. in print). The impact of this age skewed distribution is difficult to predict. It is possible that our regression equations are not as fit for younger individuals. Likewise, the equations of Baker and Newman (1957) may be somewhat unfit to use in older individuals because their sample was composed of younger individuals who served in the army. Also, the effect of age on skeletal mass is well known, especially among females due to higher prevalence of osteoporosis after menopause (Brickley, 2002; Curate et al., 2013). Nonetheless, we intentionally and naïvely assumed that skeletal mass changes would affect the entire skeleton in roughly the same way although this assumption is not entirely supported both by previous studies (Riggs et al., 1981; Riggs and Melton III, 1986) and by the values of correlation that were found between each specific bone and the total skeleton. Most bones presented quite similar correlations, that ranged from 0.77 to 0.94 , but this was not the case for the left MC4 (0.68) and the right second cuneiform (0.71). Differences in macroscopical bone composition (trabecular and cortical) or bone differences in weight bearing certainly influenced the strength of the correlations (Bonnick, 2010). Nonetheless, we believe that the formulation of regression equations that are specific to each sex, age group, or any other parameters, although probably able to render better predictions, would impair their applicability dramatically in many cases since those parameters are often unknown. Besides that, our sample was not sufficiently large and variable in terms of age at death to allow this kind of analysis. Additional investigation on a more adequate sample may help further determine how valid the 'one for all' assumption is.

A positive skew was found in the distribution of skeletal mass values. In addition, frequent data gaps were present in our sample. This non-normal distribution may have led to a weakening of the predictive power of the regression equations. Also, it may seem odd to use 
regression analysis to estimate total skeletal mass $(\mathrm{y})$ from each individual bone mass $(\mathrm{x})$ since the former includes the latter thus potentially leading to a collinearity problem. Nonetheless, results were quite satisfactory for some of the bones examined in this investigation and our results suggest that this method has clear potential. Further investigation in larger and better represented samples in terms of age may result in improved regression equations that are better fitted for the estimation of total adult skeletal mass.

The estimation of total skeletal mass can potentially lead to important inferences. The most obvious is the ability to assess skeletal completeness. Such information could be important to establish if very fragmentary remains correspond to the entire skeleton or whether some of its components have been allocated to other places since a skeletal inventory can be difficult to obtain in such cases. However, the benefits of skeletal mass regression may extend to other aspects relevant to bioanthropological investigation. As mentioned above, it may contribute to the estimation of the MNI and the detection of commingled remains. Another possible use for skeletal mass is sex estimation since skeletal mass is clearly sexually dimorphic (Malinowski and Porawski, 1969; McKinley, 1993; Warren and Maples, 1997; Bass and Jantz, 2004; Chirachariyavej et al., 2006; Silva et al., 2009; May, 2011; Van Deest et al., 2011; Gonçalves et al., 2013). These approaches have been used in extreme cases when other diagnostic features are rare or absent, such as in contexts involving burned skeletal remains. However, they have not been used consistently since their reliability remains questionable. That is partly due to the lack of references that can be directly and confidently applied in a case-by-case basis.

Although the regression approach investigated here focused on unburned skeletal remains it is possible that such approach can also be useful in the examination of fragmentary burned skeletal remains. A comparison of previously published papers (Lowrance and Latimer, 1957; Silva et al., 2009; Gonçalves, 2011) suggests that burned skeletal remains have the same proportional masses of unburned skeletal remains, as long as they have been homogeneously affected by similar temperatures. The application of the regression equations to burned skeletal remains was not tested in this paper but would be an interesting research target in the future. Another area of investigation, which was not addressed in this paper, refers to the potential of mass regression in immature remains since these are often poorly preserved.

\section{Acknowledgements}

The Portuguese Foundation for Science and Technology (FCT) is the funding body of the IRonBONE research project (PTDC/IVC-ANT/1201/2014); David Gonçalves and Francisco Curate are also funded by FCT through postdoctoral research grants (SFRH/BPD/84268/2012 and SFRH/BPD/74015/2010, respectively) and David Navega is funded through a doctoral grant (SFRH/BD/99676/2014). Catarina Coelho is funded by the University of Coimbra. Maria Teresa Ferreira is financed by Gerda Henkel Foundation ( $A Z$ 09/F/15). Our thanks go to Christopher Jardine for reviewing the paper and to Osteomics for temporarily hosting the MassReg application. We also thank the reviewers and the editor for their helpful and valuable comments on a previous version of the paper. 
Literature Cited

André A, Leahy R, Rottier S. 2013. Cremated human remains deposited in two phases: evidence from the necropolis of the Tuileries site (Lyon, France: 2nd century AD). Int J Osteoarchaeol 25(4):489-501.

Auerbach BM, Ruff CB. 2006. Limb bone bilateral asymmetry: variability and commonality among modern humans. J Hum Evol 50:203-218.

Baker P, Newman R. 1957. The use of bone weight for human identification. Am J Phys Anthropol 15:601-618.

Bass WM, Jantz RL. 2004. Cremation Weights in East Tennessee. J Forensic Sci 49(5):901-904.

Bello S, Andrews P. 2006. The intrinsic pattern of preservation of human skeletons and its influence on the interpretation of funerary behaviours. In: Gowland R, Knüsel C, editors. The Social Archaeology of Funerary Remains Oxford: Oxbow Books. p 1-13.

Bonnick S. 2010. Bone densitometry in clinical practice - Application and interpretation. Totowa: Humana Press.

Brickley M. 2002. An investigation of historical and archaeological evidence for age-related bone loss and osteoporosis. Int J Osteoarchaeol 12:364-371.

Chirachariyavej T, Amnueypol C, Sanggarnjanavanich S, Tiensuwan M. 2006. The relationship between bone and ash weight to age, body weight and body length of Thai adults after cremation. J Med Assoc Thai 89(11):1940-1945.

Collins MJ, Nielsen-Marsh CM, Hiller J, Smith Cl, Roberts JP, Prigodich RV, Wess TJ, Csàpo J, Millard AR, Turner-Walker G. 2002. The survival of organic matter in bone: a review. Archaeometry 44(3):383-394.

Curate F, Albuquerque A, Correia J, Ferreira I, Pedroso de Lima J, Cunha E. 2013. A glimpse from the past: osteoporosis and osteoporotic fractures in a Portuguese identified skeletal sample. Acta Reumatol Port 38: 20-27.

Defleur A, White T, Valensi P, Slimak L, Crégut-Bonnoure É. 1999. Neanderthal Cannibalism at Moula-Guercy, Ardèche. Science 286:128-131.

Duday H, Depierre G, Janin T. 2000. Validation des paramètres de quantification, protocoles et stratégies dans l'étude anthropologique des sépultures secondaires à incinération. L'exemple des nécropoles protohistoriques du midi de la France. In: Dedet B, Gruat P, Marchand G, Py M, Schwaller M, editors. Archéologie de La Mort, Archéologie de la Tombe au Premier Âge du -Fer. Lattes: UMR. p 7-29.

Duday H, Guillon M. 2006. Understanding the circumstances of decomposition when the body is skeletonized. In: Schmitt A, Cunha E, Pinheiro J, editors. Forensic Anthropology and Medicine. Totowa, New Jersey: Humana Press. p 117-158. 
Ferreira MT, Vicente R, Navega D, Gonçalves D, Curate F, Cunha E. 2014. A new forensic collection housed at the University of Coimbra, Portugal: The 21st century identified skeletal collection. Forensic Sci Int 245:202.e201-202.e205.

Gonçalves D. 2011. Cremains: the value of quantitative analysis for the bioanthropological research of burned human skeletal remains Coimbra: Universidade de Coimbra.

Gonçalves D, Campanacho V, Thompson TJU, Mataloto R. 2015. The weight of the matter: examining the potential of skeletal weight for the bioarchaeological analysis of cremation at the Iron Age necropolis of Tera (Portugal). In: Thompson TJU, editor. The Archaeology of cremation: Burned human remains in funerary studies. Oxford: Oxbow Books. p 63-96.

Gonçalves D, Cunha E, Thompson TJU. 2013. Weight references for burned human skeletal remains from Portuguese samples. J Forensic Sci 58(5):1134-1140.

Ingalls NW. 1931. Observations on bone weights. Am J Anat 48:45-98.

Kranioti EF, İşcan MY, Michalodimitrakis M. 2008. Craniometric analysis of the modern Cretan population. Forensic Sci Int 180(2-3):110.e111-110.e115.

Lowrance EW, Latimer HB. 1957. Weights and linear measurements of 105 human skeletons from Asia. Am J Anat 101:445-459.

Malinowski A, Porawski R. 1969. Identifikations Möglichkeiten menschlicher Brandknochen mit besonder Berücksichtigung ihres Gewichts. Zacchia 5:1-19.

Madentzoglou M, Nathena D, Michalodimitrakis M, Kranioti E. In print. The Cretan collection: a contemporary skeletal collection from Crete, Greece. Open Forensic Sci J.

Maroco JP. 2014. Análise Estatística com o SPSS Statistics. Pêro Pinheiro: Report Number.

Matiegka J. 1921. The testing of physical efficiency. Am J Phys Anthropol IV:223-230.

May SE. 2011. The Effects of Body Mass on Cremation Weight. J Forensic Sci 56(1):3-9.

Mays S. 1992. Taphonomic factors in a human skeletal assemblage. Circaea 9: 54-58.

Mays S. 2002. Asymmetry in metacarpal cortical bone in a collection of British post-mediaeval human skeletons. J Archaeol Sci 29:435-441.

McKinley J. 1993. Bone fragment size and weights of bone from British cremations and the implications for the interpretation of archaeological cremations. Int J Osteoarchaeol 3(4):283287.

Quatrehomme G. 2015. Traité d’anthropologie médico-legal. Louvain-la-Neuve: DeBoeck.

R Development Core Team. 2015. R: A language and environment for statistical computing. Vienna, Austria: R Foundation for Statistical Computing. URL http://www.R-project.org/.

Riggs BL, and Merton III LJ. 1986. Involution osteoporosis. N Engl J Med 314(26):1676-1686. 
Riggs BL, Wahner HW, Dunn WL, Mazess RB, Offord KP, and Merton III L. 1981. Differential changes in bone mineral density of the appendicular and axial skeleton with aging: relationship to spinal osteoporosis. J Clin Invest 67(2):328-335.

Rissech C, Steadman DW. 2011. The demographic, socio-economic and temporal contextualisation of the Universitat Autònoma de Barcelona collection of identified human skeletons (UAB collection). Int J Osteoarchaeol 21(3):313.322.

Roksandic M. 2002. Position of skeletal remains as key to understand mortuary behavior. In: Haglund WD, and Sorg MH, editors. Advances in Forensic Taphonomy. Boca Raton: CRC Press. $p$ 95-113.

Silva AM, Crubézy E, Cunha E. 2009. Bone Weight: new reference values based on a modern Portuguese identified skeletal collection. Int J Osteoarchaeol 19(5):628-641.

Steele J, Mays S. 1995. Handedness and directional asymmetry in the long bones of the human upper limb. Int J Osteoarchaeol 5:39-49.

Trotter M. 1954. A preliminary study of estimation of weight of skeletons. Am J Phys Anthropol 12:537-551.

Ubelaker DH, Rife JL. 2007. The practice of cremation in the Roman-era cemetery Kenchreai, Greece: the perspective from archaeology and forensic science. Bioarchaeology of the Near East 1:35-57.

Van Deest TL, Murhad TA, Bartelink EJ. 2011. A re-examination of cremains weight: sex and age variation in a Northern Californian sample. J Forensic Sci 56(2):344-349.

Waldron T. 1987. The relative survival of the human skeleton: implications for paleopathology. In: Boddington A, Garland AN, Janaway RC, editors. Death, decay and reconstruction approaches to archaeology and forensic science. Manchester: Manchester University Press.

Warren MW, Maples WR. 1997. The anthropometry of contemporary commercial cremation. J Forensic Sci 42(3):417-423.

Willey P, Galloway A, Snyder L. 1997. Bone mineral density and survival of elements and element portions in the bones of the Crow Creek massacre victims. Am J Phys Anthropol 104:513-528.

Table 1. Relative directional asymmetry (\%DA) and descriptive and inferential statistics for the mean differences between the left and the right antimeres of each bone.

\begin{tabular}{|c|c|c|c|c|}
\hline Bone & \%DA & Statistic & p-value & $n$ \\
\hline Clavicle & 0.000 & 370.000 & 0.595 & 41 \\
\hline
\end{tabular}




\begin{tabular}{|c|c|c|c|c|}
\hline $\mathrm{MCl}$ & 2.985 & 274.000 & 0.694 & 37 \\
\hline MC II & 3.369 & 190.000 & 0.067 & 38 \\
\hline MC III & 4.000 & 128.500 & 0.004 & 39 \\
\hline MCIV & 3.774 & 107.500 & 0.030 & 37 \\
\hline $\mathrm{MC} \mathrm{V}$ & 4.725 & 116.000 & 0.049 & 36 \\
\hline Patella & 2.429 & 226.000 & 0.483 & 33 \\
\hline Calcaneus & 1.692 & 415.000 & 0.172 & 47 \\
\hline Talus & 2.429 & 426.000 & 0.042 & 51 \\
\hline Cuboid & 0.000 & 497.000 & 0.392 & 49 \\
\hline Navicular & 2.299 & 365.500 & 0.285 & 47 \\
\hline Cuneiform I & 2.597 & 383.500 & 0.194 & 47 \\
\hline Cuneiform II & 3.509 & 250.500 & 0.293 & 45 \\
\hline Cuneiform III & 0.000 & 373.500 & 0.971 & 46 \\
\hline MT I & 0.662 & 352.500 & 0.218 & 46 \\
\hline MTII & 0.565 & 393.500 & 0.340 & 48 \\
\hline MT III & -1.053 & 515.500 & 0.815 & 48 \\
\hline MT IV & 3.736 & 250.000 & 0.020 & 44 \\
\hline MT V & 0.000 & 257.000 & 0.903 & 39 \\
\hline
\end{tabular}


Table 2. Intercept, slope, root mean squared error (RMSE) and explained variance (R-Squared) of univariate linear regression models according to each bone and each side.

\begin{tabular}{|c|c|c|c|c|c|c|c|c|}
\hline & \multicolumn{1}{|l}{ Left } & \multicolumn{4}{l|}{ Right } \\
\hline Bone $(x)$ & Intercept $(a)$ & Slope $(b)$ & RMSE & R-squared & Intercept $(a)$ & Slope $(b)$ & RMSE & R-squared \\
\hline Humerus & 660.806 & 23.280 & 307.090 & 0.859 & - & - & - & - \\
\hline Clavicle & 494.576 & 148.480 & 364.680 & 0.805 & 654.098 & 138.938 & 411.486 & 0.756 \\
\hline MCI & 794.155 & 806.959 & 406.326 & 0.776 & 969.264 & 724.627 & 455.077 & 0.676 \\
\hline MC II & 775.494 & 506.224 & 346.089 & 0.822 & 845.056 & 493.505 & 459.849 & 0.670 \\
\hline MC III & 803.442 & 553.22 & 433.468 & 0.677 & 652.539 & 561.11 & 415.941 & 0.746 \\
\hline MC IV & 1098.979 & 812.583 & 561.812 & 0.403 & 1023.933 & 788.089 & 492.762 & 0.592 \\
\hline MC V & 1047.284 & 973.989 & 441.949 & 0.613 & 1087.873 & 923.897 & 521.917 & 0.563 \\
\hline Femur & 452.783 & 8.439 & 292.894 & 0.872 & - & - & - & - \\
\hline Patella & 759.462 & 233.389 & 403.533 & 0.743 & 917.936 & 211.817 & 497.095 & 0.626 \\
\hline Calcaneus & 1133.193 & 76.802 & 399.015 & 0.752 & 1228.794 & 71.269 & 435.780 & 0.729 \\
\hline Talus & 871.382 & 134.109 & 400.982 & 0.766 & 862.272 & 131.811 & 424.576 & 0.749 \\
\hline
\end{tabular}


Table 2. Intercept, slope, root mean squared error (RMSE) and explained variance (R-Squared) of univariate linear regression models according to each bone and each side (cont.).

\begin{tabular}{|c|c|c|c|c|c|c|c|c|}
\hline \multicolumn{1}{|l|}{ Left } \\
\hline Bone $(x)$ & Intercept $(a)$ & Slope $(b)$ & RMSE & R-squared & Intercept $(a)$ & Slope $(b)$ & RMSE & R-squared \\
\hline Cuboid & 1005.395 & 445.746 & 435.727 & 0.722 & 940.963 & 461.524 & 427.538 & 0.746 \\
\hline Navicular & 1233.235 & 369.652 & 487.674 & 0.644 & 1080.91 & 402.445 & 449.858 & 0.729 \\
\hline Cuneiform I & 962.247 & 530.002 & 447.222 & 0.700 & 1060.064 & 500.895 & 426.964 & 0.754 \\
\hline Cuneiform II & 1207.161 & 1090.729 & 548.408 & 0.565 & 1479.411 & 867.963 & 599.774 & 0.434 \\
\hline Cuneiform III & 1212.037 & 822.907 & 483.077 & 0.664 & 1037.715 & 881.345 & 437.058 & 0.745 \\
\hline MT I & 892.175 & 299.168 & 460.579 & 0.678 & 963.266 & 283.768 & 429.269 & 0.750 \\
\hline MT II & 1205.857 & 434.588 & 514.372 & 0.634 & 1066.276 & 461.392 & 447.362 & 0.725 \\
\hline MT III & 924.793 & 557.408 & 536.143 & 0.589 & 894.369 & 571.026 & 519.413 & 0.625 \\
\hline MT IV & 818.794 & 621.027 & 486.594 & 0.657 & 839.228 & 591.057 & 522.564 & 0.626 \\
\hline MT V & 1134.667 & 464.344 & 522.627 & 0.629 & 1380.536 & 409.376 & 570.064 & 0.572 \\
\hline
\end{tabular}

